\title{
Optimal Placement of DG with Battery Energy Storage in Distribution Network for Power loss Minimization using Combined Dispatch \& Combined PLS Strategy
}

\author{
Bharat Singh, Satyaveer Singh Rawat
}

\begin{abstract}
This paper presents a novel application of General Algebraic Modelling System (GAMS) and MATLAB interfacing for optimal location and placement of DG with battery. The main contribution of this paper is: (i) optimal placement of DG based on combined-Power Loss Sensitivity (PLS) method, (ii) optimal placement of battery energy storage using combined dispatch strategy, (iii) optimal size of DGs and Battery have been carried out in such a way to minimize the total power loss without violating the constraints using MINLP solver in GAMS . (iv) Two types of DGs have been considered for analysis and the impact of $D G$ with and without battery placement on total power loss and voltage improvement. Voltage profile, real and reactive power flow pattern, total power loss, computational time, fuel cost, total installation cost, total cost, State of Charge (SOC) status of battery and power obtain by $D G$ with the battery has been determined. The result shows the importance of DG with battery size and location. The results are obtained on IEEE-33bus radial distribution test system and compare with another existing method also.

Keywords: Distribution Generation, Battery Storage, radial distribution system, Renewable Energy Sources, Power loss minimization.
\end{abstract}

\section{I.INTRODUCTION}

T become integral part of the power system network. The distributed generation (DGs) with renewable sources and its penetration into the distribution network has introduced lot of challenges to the distribution network operator for better management and planning. In this context, the distribution system analysis need to be analyzed with DGs. The storage devices have become part of the AC/DC micro grids with the renewable sources to meet out the deviations in the power requirement during their intermittency. Therefore, there is utmost need to analyze such hybrid power system for optimal dispatch strategy satisfying the criteria of loss minimization. In this paper work, we have considered a 33bus radial distribution for analysis that consists of batteries and diesel generators. Each generating unit is first mathematically modeled. For simplicity, current modeling is used, in which the output and input of each generating unit are expressed in terms of current.

Revised Manuscript Received on June 15, 2020.

*Correspondence Author

Bharat Singh*, Electrical Engineering department, NIT Kurukshetra, Haryana, India. Email: bharat_6180045@nitkkr.ac.in

Satyaveer Singh Rawat, IEEE member, Assistant Professor in Electrical Engineering Depp. GBPEC, Pauri UK, India, ssr09fee@gbpec.ac.in, satya.firststep@gmail.com

(C) The Authors. Published by Blue Eyes Intelligence Engineering and Sciences Publication (BEIESP). This is an open access article under the CC BY-NC-ND license (http://creativecommons.org/licenses/by-nc-nd/4.0/)
A lot of literature has been done for the placement of renewable-based Distribution Generation (DGs). The loss sensitivity factor (LSF) method is presented in [1] for the location and sizing of DGs. A research based on the single variable and multi-variable approach using Particle Swarm Optimization (PSO) algorithm to find out the best location and optimal size of DG represented in [2]. The MINLP approach has been used for location of DGs in [3]. The multi-source has represented better reliability then single source energy system in [4]. Dufo-Lopez et al. [5] has represented the multi-objective genetic algorithm for cost calculation of hybrid energy sources along with battery energy storage. The DGs placement have also been used for the voltage enhancement using PSO algorithm [6]. In many of the research paper the PSO algorithm was implemented [7] -[8].

The power flow has been solved using direct approach by Teng.j et.al [9]. The battery storage has not considered with DG using power Loss [10]. The GA technique has used for multi-objective function by k. Vinod Kumar et.al [11] to obtain the DGs position. In the above literature the battery storage has not been taken into account with DG [6]-[11].

The power loss minimization has become another issue for the placement of DGs along with the battery storage. In this context the total power loss minimization with installation of DGs has been done in [12].

The optimal position of battery storage has become essential task for the Microgrid (MG) operator. The installation of battery storage has been done using the dispatch strategy represented in [13]. The cycling and load following battery dispatch strategy has considered with solar energy for cost based analysis in [14]. The cost based energy storage system has also been done for energy management system in [15], [16] [17] and [18].

In this paper work, the DG size and location with and without storage device has been determined. First, the candidate bus for DG placement based on the sensitivity approach, the MINLP technique was used to determine the size of DG. The combined power loss sensitivity approach and the combined dispatch strategy have been used for location of DGs and battery storage respectively. Whereas the MINLP used of the sizing of DGs and battery storage.

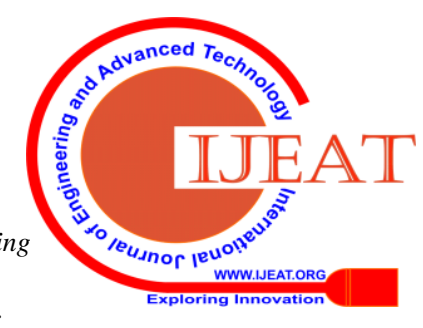


The MATLAB and GAMS interfacing has been utilized for obtaining the optimal solution. On the other hand, the battery energy storage device has been integrated with DG in such a way to meet out the power mismatch.

In this paper the two cases are taken: in first case- DGs at unity, 0.9 lagging and combined load power factor have been considered. The combined-PLS is computed for distribution network with and without DGs. The dynamic load also consider on the basis of 24 hours changing in nature. In the second case- the DG with battery storage has been consider. The battery storage with dispatch strategy [13] is used to obtain the location of the energy storage device.

\section{II.PROBLEM FORMULATION AND MATHEMATICAL MODEL}

The main objective of this paper is to obtain the optimal size and location of DGs with and without battery storage for power loss minimization. The single objective problem of this paper has been solved in two part as follows;

In first part, the position of DG's and battery storage has been obtained.

- The location of DGs is obtained using the combined power loss sensitivity (PLS) in MATLAB [12].

- The position of battery energy storage is obtained using the Combined dispatch strategy in MATLAB [13].

In second part of this paper;

- The sizing of DGs and battery storage have been determined at the obtained location of first part using MINLP in GAMS.

GAMS is designed for modeling linear, nonlinear and mixed integer optimization problems.

In this paperwork, the IEEE 33 bus test system has been carried out. The time-varying ZIP load has been taken into account for the analysis. The impact of battery energy storage with and without renewable energy sources has also been analysed. The unit commitment problem has been formulated, including piecewise cost segment, ramp rate, minimum uptime and downtime constraints. The problem is solved by MINLP solver in GAMS. The data interpretation has been done with the interfacing of MATLAB and GAMS software.

\section{A. Mathematical Modelling}

In this section the mathematical modelling of Solar, Wind Turbine, Fuel Cell, Micro-Turbine and battery storage has been represented as follows;

\section{1) Radial Distribution System}

The IEEE -33 bus test system has been carried out for the analysis, with 24 hours load variation, Distribution Generator (DG) and batteries. The schematic representation of the radial distribution power system is shown in Fig.1.

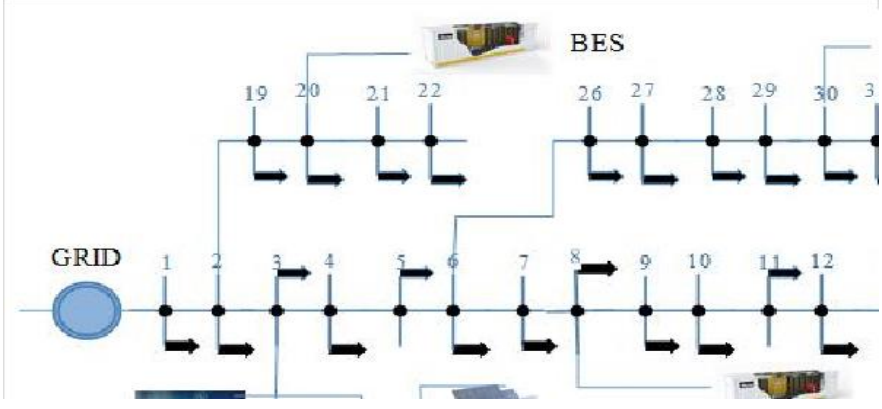

Fig. 1 Radial Distribution system with Energy Sources

\section{2) Battery Model}

The battery storage works as backup storage. It can either be charged or dis-charged according to the dispatch strategy [20]. The state of charge has been cal-culated for each battery. The maximum value depends on the nominal capacity while the minimum value on its Depth of Discharge (DOD).

$$
S O C_{\min }=N_{\text {batt }} C_{n b}\left(1-D O D_{\text {max _bat }}\right)
$$

$$
S O C_{\text {max }}=N_{\text {batt }} * C_{n b}
$$

$\operatorname{SOC}(k+\Delta k)=\operatorname{SOC}(k) \cdot\left(1-\delta_{k}\right)+\left(P_{c h} \cdot \eta_{c h}-\right.$

$\left.P_{\text {dis }} \cdot \frac{1}{\eta_{\text {dis }}}\right) \cdot \Delta k$

Constraints:

$$
\begin{aligned}
& \operatorname{SOC}_{i}^{\min }(k) \leq S O C_{i}(k) \leq \operatorname{SOC}_{i}^{\max }(k) \\
& P_{\text {ch_min }}{ }_{i}^{k} \leq P_{c h}{ }^{k} \leq P_{\text {ch_max }}{ }_{i}^{k} \\
& P_{\text {dis_min }_{i}}^{k} \leq P_{\text {dis }}{ }_{i}^{k} \leq P_{\text {dis_max }_{i}}^{k}
\end{aligned}
$$

where, $N_{b a t t}$ is the no of battery, $C_{n b}$ is the nominal capacity of the battery, $\delta_{-} k$ is the depth of discharge at the kth time, $P_{c h}{ }^{k}$ and $P_{d i s}{ }_{i}^{k}$ is the charging and discharging power of battery at the kth time respectively. $\eta_{-} c h$ and $\eta_{-} d i s$ is the charging and discharging efficiency of the battery respectively.

\section{3) Solar Photovoltaic Model}

The solar PV is renewable based green energy source, in Fig.2 the output curve is shown, The solar model of PV has been represented as follows;

$$
P_{\text {solar }}\left(I_{\beta}\right)=N_{P V} \cdot P_{\text {rated }}^{P V} \frac{G}{G 0} \cdot\left\{1-T_{c}\left(T_{A}-25\right)\right\} \cdot \eta_{\text {inv }} \eta_{r l}
$$

(6) where, $P_{\text {solar }}$ is the output power, $P_{\text {rated }}^{P V}$ rated power of PV, and $N_{P V}$ is the total number of solar panel [19]. $G$ and $G 0$ are solar irradiation and slandered solar irradiation in $\left(\frac{w a t t}{m^{2}}\right)$.

The Fig. 2 shows solar PV output for 24 hours. $T_{A}$ is the ambient temperature and Tc is the temperature coefficient of the maximum power of PV. $\eta_{-} i n v$ and $\eta_{-} r l$ represent the efficiency of the inverter and the relative efficiency of the PV modules respectively.
Published By:

Blue Eyes Intelligence Engineering

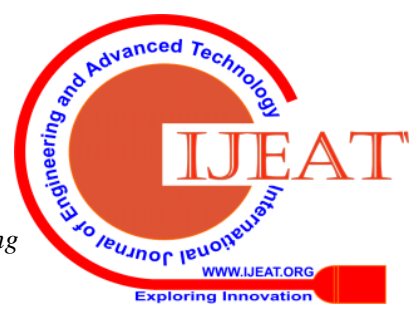




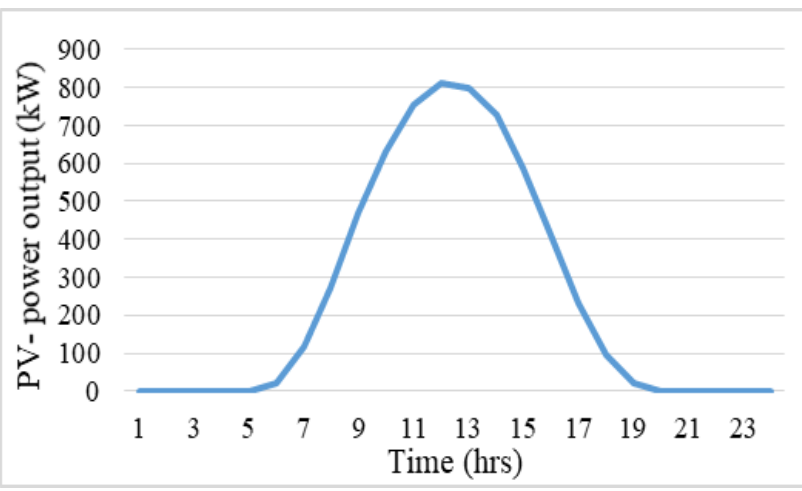

Fig.2 Solar power output curve for 24 hrs

\section{4) Wind Turbine Generator}

In this paper, the liner model of wind power output has been taken into account. In Fig.3 the output curve of wind turbine is shown.

$$
P_{\text {wind }}=\left\{P_{\text {rated }}\left(\frac{\left(v-v_{\text {in }}\right)^{2}}{\left(v_{r}-v_{\text {in }}\right)^{2}}\right) ; v_{\text {in }} \leq v \leq\right.
$$

$v_{r} P_{\text {rated }} ;$

$v_{r} \leq v \leq v_{\text {out }}$

$v_{\text {out }}$ and $v<v_{\text {cut }}$

where, $P_{\text {rated }}$ is the rated Wind Turbine power, $P_{\text {wind }}$ is the Wind-Turbine power output $v_{\text {in }}$ is cut in the velocity of Wind Turbine, $v_{\text {out }}$ is cut out Wind Turbine velocity

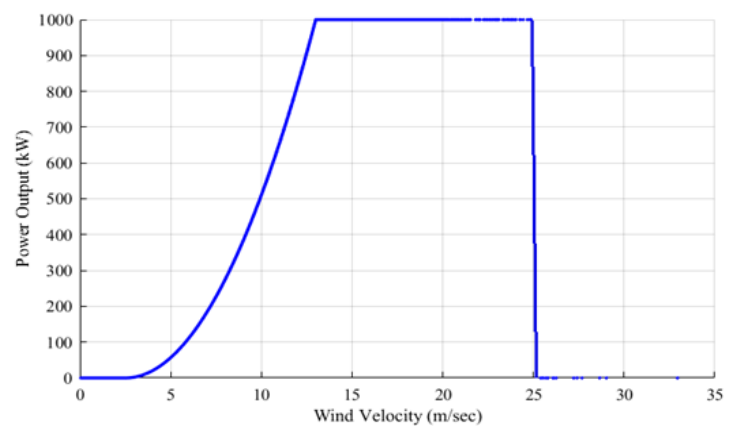

Fig. 3 Wind Turbine power output curve

\section{5) Combined Power Loss Sensitivity Method (CPLS).}

This method [10] considers both active and reactive power loss for the formulation of sensitivity factors. The bus with highest sensitivity factor for which normalized sensitivity value is less than 0.0015 is chosen as the location for placement DG. The formulation for sensitivity factors are as follows;

$$
\begin{aligned}
& \frac{\partial P_{l o s s}^{k}}{\partial Q_{i}^{k}}=\frac{2 Q_{i}^{k} R_{l}}{\left(V_{i}^{k}\right)^{2}} ; \frac{\partial P_{\text {loss }}^{k}}{\partial P_{i}^{k}}=\frac{2 P_{i}^{k} R_{l}}{\left(V_{i}^{k}\right)^{2}} \\
& \frac{\partial Q_{\text {loss }}^{k}}{\partial Q_{i}^{k}}=\frac{2 Q_{i}^{k} X_{l}}{\left(V_{i}^{k}\right)^{2}} ; \frac{\partial Q_{l o s s}^{k}}{\partial P_{i}^{k}}=\frac{2 P_{i}^{k} X_{l}}{\left(V_{i}^{k}\right)^{2}}
\end{aligned}
$$

combined loss sensitivity with respect to reactive power is given by

$$
\begin{aligned}
& \frac{\partial S_{\text {loss }}^{k}}{\partial P_{i}^{k}}=\frac{\partial P_{\text {loss }}^{k}}{\partial P_{i}^{k}}+j \frac{\partial Q_{\text {loss }}^{k}}{\partial P_{i}^{k}} \\
& \frac{\partial S_{\text {loss }}^{k}}{\partial Q_{i}^{k}}=\frac{\partial P_{\text {loss }}^{k}}{\partial Q_{i}^{k}}+j \frac{\partial Q_{\text {loss }}^{k}}{\partial Q_{i}^{k}}
\end{aligned}
$$

\section{6) Distribution ZIP load model}

In this paper, the time-varying ZIP load model is represented. The constant impedance, constant current and constant power load model for residential, commercial and industrial loads has been carried out for the analysis.
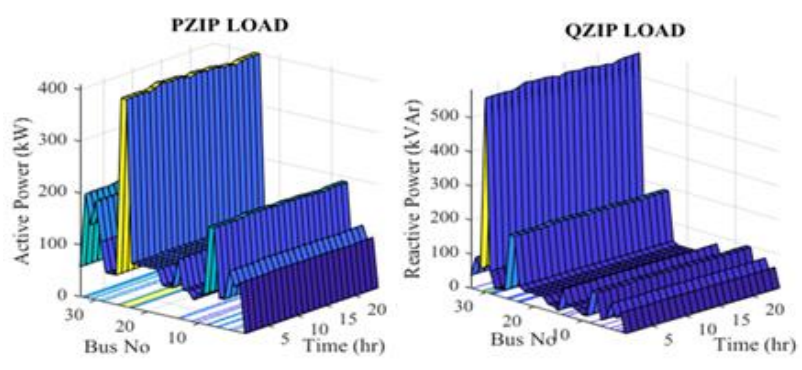

Fig.4 ZIP Load profile

The expressions for zip load model is represented as follows;

$$
\begin{aligned}
& P_{i, k}^{Z I P}=P d_{i}\left[Z_{p}\left(\frac{V_{i}^{k}}{V_{\text {min }}^{k}}\right)^{2}+I_{p}\left(\frac{V_{i}^{k}}{V_{\text {min }}^{k}}\right)+P_{p}\right] \\
& Q_{i, k}^{Z I P}=Q d_{i}\left[Z_{q}\left(\frac{V_{i}^{k}}{V_{\text {min }}^{k}}\right)^{2}+I_{q}\left(\frac{V_{i}^{k}}{V_{\text {min }}^{k}}\right)+P_{q}\right]
\end{aligned}
$$

$\forall\left\{Z_{i}+I_{i}+P_{i}=1\right\}$, where, $Z_{i}, I_{i}$ and $P_{i}$ are the constant impedance, constant current and constant power load parameter for different type of costumer [20]. $P d_{i}$ and $Q d_{i}$ are the load demand at each bus i. The active and reactive part of ZIP load is shown in Fig.4.

\section{A. B Mathematical model formulation}

The following objective function has formulated as: Optimal power flow formulation.

Optimal power flow is formulated by minimizing the total power loss which is given by the equations

Minimize

$O F=\sqrt{\left[\left(\sum_{i, j=1}^{k} \quad P L_{i j}\right)^{2}+\left(\sum_{i, j=1}^{k} \quad Q L_{i j}\right)^{2}\right]}$

Constraints Equation:

(i). Power balance constraints;

$$
P_{i}^{k}=P_{D G i}^{k}+P_{d i s, i}^{k}-P_{c h, i}^{k}-P_{i, k}^{Z I P}
$$

$=V_{i}^{k} \sum_{j=1}^{n} V_{j}^{k}\left(G_{i j}^{k} \cos \cos \left(\delta_{i}^{k}-\delta_{j}^{k}\right)+B_{i j}^{k}\right.$

$\left.\sin \sin \left(\delta_{i}^{k}-\delta_{j}^{k}\right)\right)$

, $i \in S_{B} \& k \in S_{T}$

$Q_{i}^{k}=Q_{D G, i}^{k}-Q_{i, k}^{Z I P}=V_{i}^{k} \sum_{j=1}^{n} \quad V_{j}^{k}\left(G_{i j}^{k} \sin \sin \left(\delta_{i}^{k}-\right.\right.$ $\left.\left.\delta_{j}^{k}\right)-B_{i j}^{k} \cos \cos \left(\delta_{i}^{k}-\delta_{j}^{k}\right)\right), i \in S_{B} \& k \in S_{T}$

where $\forall i=1,2 \ldots . n b, \forall i j=1,2 \ldots . n l, n b$ is a number of buses and $n l$ is the total number of line. $\forall k=1,2 \ldots .24$ is the set of time. $P_{i}^{k}$ is the total active power injected at the ith bus for kth hours. $P_{i, k}^{Z I P}$ is the total active power demand of ZIP Load at ith bus for kth hours. $Q_{i, k}^{Z I P}$ is the total reactive power demand of ZIP Load at ith bus for kth hours.

(ii) DG's power Limits

$P_{D G, i}^{\min } \leq P_{D G, i}^{k} \leq P_{D G, i}^{\max }$

$Q_{D G, i}^{\min } \leq Q_{D G, i}^{k} \leq Q_{D G, i}^{\max }$

(iii) Limits for voltage and angle

Published By:

Blue Eyes Intelligence Engineering

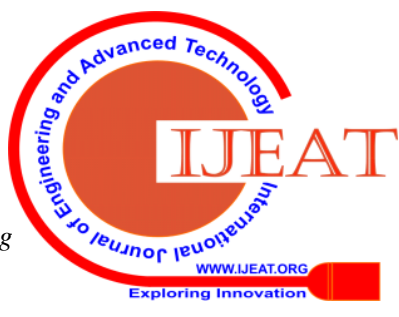


$V_{i}^{\min } \leq V_{i}^{k} \leq V_{i}^{\max }, i \in S_{B}$

$\delta_{i}^{\text {min }} \leq \delta_{i}^{k} \leq \delta_{i}^{\max } \forall i=1,2 \ldots . n b$

(iv) Line loss limit

$\left|P l^{k}\right|=\left|P_{i j}^{k}\right|=\mid V_{i}^{k} V_{j}^{k}\left(G_{i j}^{k} \cos \cos \left(\delta_{i}^{k}-\delta_{i}^{k}\right)+B_{i j}^{k}\right.$

$\left.\cos \cos \left(\delta_{i}^{k}-\delta_{i}^{k}\right)\right)-\left(V_{i}^{k}\right)^{2} G_{i j}^{k} \mid \leq P l_{\text {max }}^{k}, l \in S_{L}$

where, $S_{B}$ represent the set of Bus i

(v) Transmission line sending end and receiving end constraints

$P_{f_{\text {smin }}{ }_{j}}^{k} \leq P_{f s_{j}} \leq P_{\text {ssmax }_{j}}^{k}, i \in S_{f s}$

$Q_{f \operatorname{smin}_{i}}^{k} \leq Q_{f s_{j}} \leq Q_{f \operatorname{smax}_{j}}^{k}, i \in S_{f s}$

$P_{\text {frmin }_{j}}^{k} \leq P_{f r_{j}} \leq P_{\text {frmax }_{j}}^{k}, i \in S_{f r}$

$Q_{\text {frmin }_{i}}^{k} \leq Q_{f r_{j}} \leq Q_{\text {frmax }_{j}}^{k}, i \in S_{f r}$

where, $S_{f s}, S_{f s}$ represents the set of Bus i for sending and receiving end power flow.

\subsection{Dispatch Strategy}

In this model, the DG and storage device as a battery have been with an objective to minimize the total power loss and cost of the system. In order to maximize the reliability and yet maintain the cost along with minimum power loss, different dispatch strategies like as Load following strategy, Cycle charging strategy or combined strategy can be used [5], [13]. In this paper the combined strategy is implemented for the location of energy storage device as batteries.

\section{III.ALGORITHM USED}

The various steps involved in finding the optimal location and sizing of DGs with and without batteries in such a way to minimize the total power losses in distribution system summarized as:

Step 1: Read the system data for IEEE 33-bus radial distribution system.

Step 2: Run the load flow program for the 24-hour load data and obtain the base case for total power losses.

Step 3: Obtain the PLS at each node for 24 hours based on the distribution load flow. Select the node having the highest PLS factor for the position of DGs.

Step 4: Obtain the position of batteries at each node for 24 hours using dispatch strategy [13], in the form of a matrix (bus, hours). Save the position set of battery storage to obtain the size at each node.

Step 5: Transfer the all control parameter from MATLAB to GAMS using interfacing.

Step 6: Solve the optimal load flow for optimal size of DGs with and without batteries, calculate the SOC using MINLP solver to minimize the total power loss.

Step 7: Transfer the objective variables form GAMS to MATLAB.

Step 8: Print the results.
The flow chart (1199)shown in Fig.5.

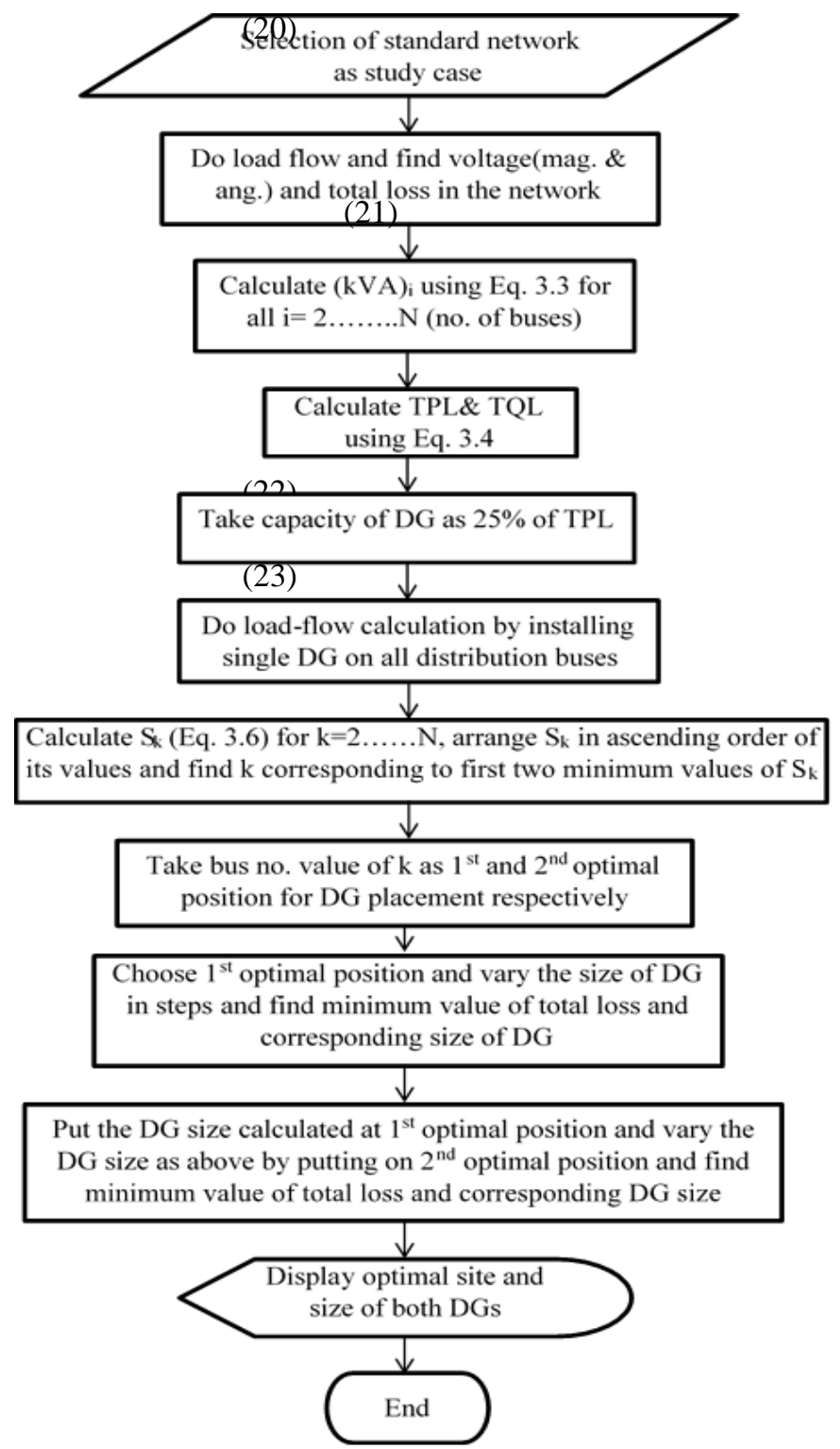

Fig. 5. Flow chart for the algorithm used

\section{IV.SYSTEM DATA}

The system data are given in this paper represented as follows;

\section{A. Load data and Market price data}

The ZIP load data [35] for the residential, commercial, and industrial consumers are given in Table I.

Table- I: Cost coefficients of ZIP load for various customers

\begin{tabular}{|l|l|l|l|l|l|l|}
\hline Type & $\mathbf{Z p}$ & $\mathbf{I} \boldsymbol{p}$ & $\mathbf{P p}$ & $\mathbf{Z q}$ & $\mathbf{I q}$ & $\mathbf{P q}$ \\
\hline Residential & 0.414 & 0.136 & 0.450 & 0.160 & 0.375 & 0.465 \\
\hline Commercial & 0.860 & -0.160 & 0.300 & 0.60 & 0.660 & -0.260 \\
\hline Industrial & 0 & 0 & 1 & 0 & 0 & 1 \\
\hline
\end{tabular}

The percentage of load demand in residential, commercial and industrial are shown in Table II.

Table- II: Percentage of demand for various

Published By:

Blue Eyes Intelligence Engineering

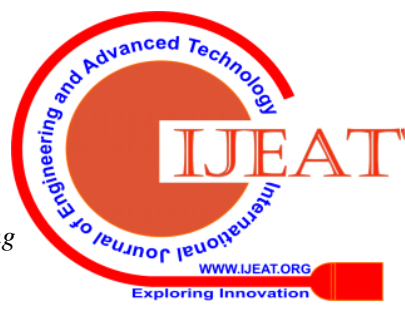


customers and market price

\begin{tabular}{|c|c|c|c|c|}
\hline Time & Res & Com & Indu. & $\begin{array}{c}\text { Market } \\
\text { Price }\end{array}$ \\
\hline t1 & 0.66 & 0.17 & 0.17 & 0.11 \\
\hline t2 & 0.63 & 0.17 & 0.20 & 0.10 \\
\hline t3 & 0.60 & 0.18 & 0.22 & 0.11 \\
\hline t4 & 0.58 & 0.20 & 0.22 & 0.09 \\
\hline t5 & 0.60 & 0.23 & 0.17 & 0.11 \\
\hline t6 & 0.55 & 0.15 & 0.30 & 0.11 \\
\hline t7 & 0.30 & 0.14 & 0.56 & 0.13 \\
\hline t8 & 0.11 & 0.32 & 0.57 & 0.15 \\
\hline t9 & 0.10 & 0.34 & 0.56 & 0.26 \\
\hline t10 & 0.11 & 0.33 & 0.56 & 0.30 \\
\hline t11 & 0.12 & 0.37 & 0.51 & 0.35 \\
\hline t12 & 0.17 & 0.46 & 0.37 & 0.40 \\
\hline t13 & 0.14 & 0.37 & 0.49 & 0.50 \\
\hline t14 & 0.14 & 0.39 & 0.47 & 0.40 \\
\hline t15 & 0.15 & 0.46 & 0.39 & 0.30 \\
\hline t16 & 0.18 & 0.41 & 0.41 & 0.30 \\
\hline t17 & 0.20 & 0.44 & 0.36 & 0.40 \\
\hline t18 & 0.33 & 0.47 & 0.20 & 0.50 \\
\hline t19 & 0.60 & 0.30 & 0.10 & 0.30 \\
\hline t20 & 0.70 & 0.23 & 0.06 & 0.26 \\
\hline t21 & 0.74 & 0.19 & 0.07 & 0.15 \\
\hline t22 & 0.76 & 0.15 & 0.09 & 0.13 \\
\hline t23 & 0.75 & 0.15 & 0.10 & 0.10 \\
\hline t24 & 0.71 & 0.16 & 0.13 & 0.11 \\
\hline & & & & \\
\hline
\end{tabular}

B. Solar and Wind Turbine cost data

Table- IV: The input data for the energy sources

\begin{tabular}{|l|l|l|l|l|l|}
\hline & $\begin{array}{l}\text { Acquisit } \\
\text { ion cost } \\
\mathbf{( \$ )}\end{array}$ & $\begin{array}{l}\text { Operation } \\
\text { and } \\
\text { Maintenance } \\
\text { Cost } \\
\text { (\$/year/kW) }\end{array}$ & $\begin{array}{l}\text { Replacem } \\
\text { ent } \\
\text { Cost } \\
\mathbf{( \$ / L i f e t i ~} \\
\text { me) }\end{array}$ & $\begin{array}{l}\text { Lifes } \\
\text { pan } \\
\text { (year) }\end{array}$ & Rating \\
\hline $\begin{array}{l}\text { PV } \\
\text { module }\end{array}$ & 2400 & 18 & $\begin{array}{l}2.85 \text { @ } \\
\text { 25 year of } \\
\text { life time }\end{array}$ & 25 & $\begin{array}{l}800 \\
(\mathrm{~kW})\end{array}$ \\
\hline $\begin{array}{l}\text { Wind } \\
\text { Turbine } \\
\text { (1MW) }\end{array}$ & 3724.5 & 31 & 3009.5 & 20 & $\begin{array}{l}1000 \\
(\mathrm{~kW})\end{array}$ \\
\hline $\begin{array}{l}\text { Battery } \\
\text { Storage }\end{array}$ & 600 & 20 & $\begin{array}{l}4.64 \text { @ } \\
1.45 \text { year }\end{array}$ & $\begin{array}{l}100 \\
(\mathrm{kWh})\end{array}$ \\
\hline
\end{tabular}

The input data used in this paper has shown in Table- IV. The cost estimation data for the PV-based DG and windbased DG have been taken from the National Renewable Energy Laboratory (NREL) [21], [22] \& [23]. The data for battery, regulators and investors are taken from the literature [24].

The Si-mono PV modules (ET -Solar maker) of PV module has been taken for the analysis in this paper.

\section{V.RESULTS AND DISCUSSION}

The energy storage system incorporated with Distribution Generation in radial distribution system under consideration has been designed by GAMS optimization tool. To demonstrate the proposed optimized algorithm by GAMS and MATLAB interfacing has been tested on IEEE-33 bus test system. In this algorithm, the optimization has been done by using GAMS optimization tool in such a way to minimize the total power loss, planning the optimum location and sizing of DGs.

In this context the DG of type- 1 and Type- 3 has been considered for analysis. In DG Type-1, operating at unity power factor and capable of injecting real power to the distribution system. Whereas the DG type-3 operating at lagging power factor and capable of injecting real and reactive power to the distribution system.

In this section two cases has been taken as follows;

- Case-1: DGs without energy storage has been considered.

- Case-2: DGs with energy storage has been considered.

In Case-1 single as well as multiple DGs has been taken into account. In Case-2; the single and multiple DGs with type- 1 and Type- 3 has been considered for analyzing the impact of battery energy storage also.

\section{A. Result for combined power loss sensitivity}

The combined power loss sensitivity approach is used to calculate the location of DGs and thus the corresponding size of DGs is obtained as explain in section II. From Fig.6 the highest PLS obtained is for at bus number 8, 24, and 25 as is shown. The criterion for selection of the optimal placement of DGs is set if PLS is greater than 0.0015, due to this bus no 20 and 31 are also be selected.

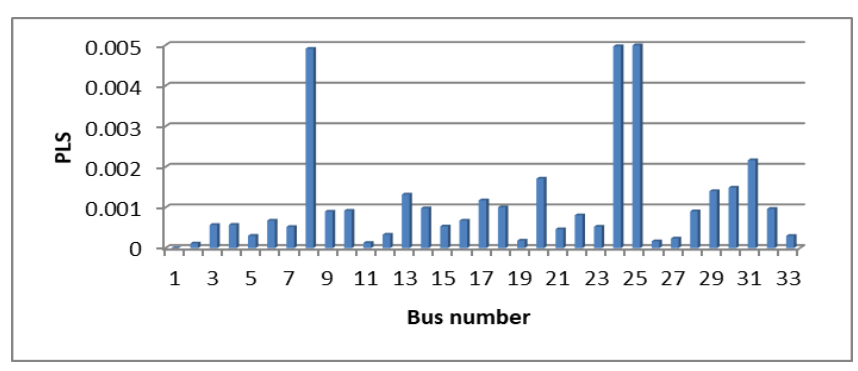

Fig. 6. PLS profile for 33-bus radial distribution system

\section{B. Case 1}

The single DG of Type- 1 at $8^{\text {th }}$ bus and obtained size is $2521.8 \mathrm{~kW}$, whereas the multiple DGs located at bus number 8,24 and 25. The obtained size of multiple DGs are $1424.9,448.84$ and $420.22 \mathrm{~kW}$ at bus number $8^{\text {th }}, 24^{\text {th }}$, and $25^{\text {th }}$ respectively. The size of DGs Type- 3 without battery storage has been shown in Fig.7 the location for the multiple DG of Type-3 located at bus number 8, 20, 24, 25 and 31. The active and reactive power rating required for DGs has also shown.

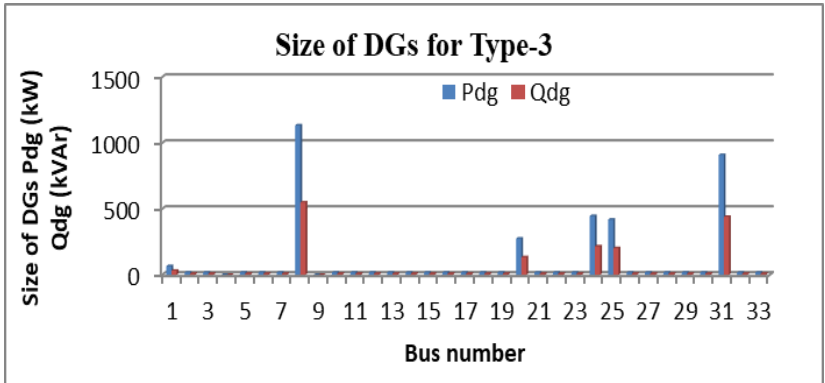

Fig.7 The size of multiple DG of Type-3 without battery storage

The Fig. 7 shows the real and reactive power for DGs of type-3.

The optimal location and placement for DGs type-3

Published By:

Blue Eyes Intelligence Engineering

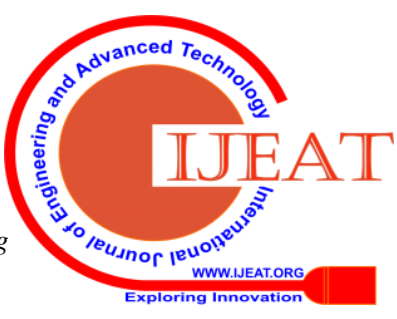


shown in Table- $\mathrm{V}$, the selection criteria is based on PLS. The higher value of PLS indicates the higher losses in the system, for selection of single DG the losses are larger, and it has been decreasing simultaneously with increasing the number of DGs. for DGs of Type-3

\section{Case 2: DGs with battery storage}

The second part of this paper is to the analysis of Battery energy storage with DGs to share the real power injection as well as to minimize the total power loss. The location and sizing of the battery energy storage are based on the combined load cycling method [20].

\section{1). Size of DGs type-1 with Battery energy storage}

Fig. 8 shows the size and location of DG for 24 hours load along with the battery. The position of multiple DGs Type1 with battery energy storage (BES) is 8, 20, 24, 25 and 31 based on the highest value of PLS.

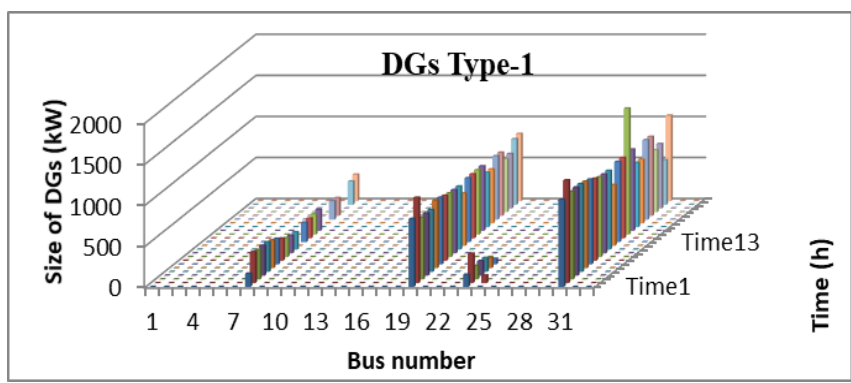

Fig. 1. DGs Type-1 profile for 24 hours load 33-bus radial distribution system

In Table $\mathrm{V}$ shows the result for the optimal size and placement of DG with battery.

The size of single DG with battery storage obtained is $1684.3 \mathrm{~kW}$ at $25^{\text {th }}$ bus. The size of battery storage obtained is $13.8 \mathrm{kWh}$. the required data for battery storage is given in section-IV.

Table V. Result for DG with Battery storage

\begin{tabular}{|c|c|c|}
\hline Method & $\begin{array}{l}\text { Optimal } \\
\text { Location }\end{array}$ & Optimal DGs Size (kW) \\
\hline \multirow{3}{*}{$\begin{array}{c}\text { Propose } \\
\mathrm{d}\end{array}$} & 25 & [1684.3] \\
\hline & $7,8,24,25$ & $\begin{array}{ll}{[1350.2,} & 1499.4 \\
446.73, & 418.68]\end{array}$ \\
\hline & $\begin{array}{c}8,20,24,25 \\
31\end{array}$ & 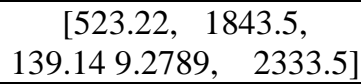 \\
\hline
\end{tabular}

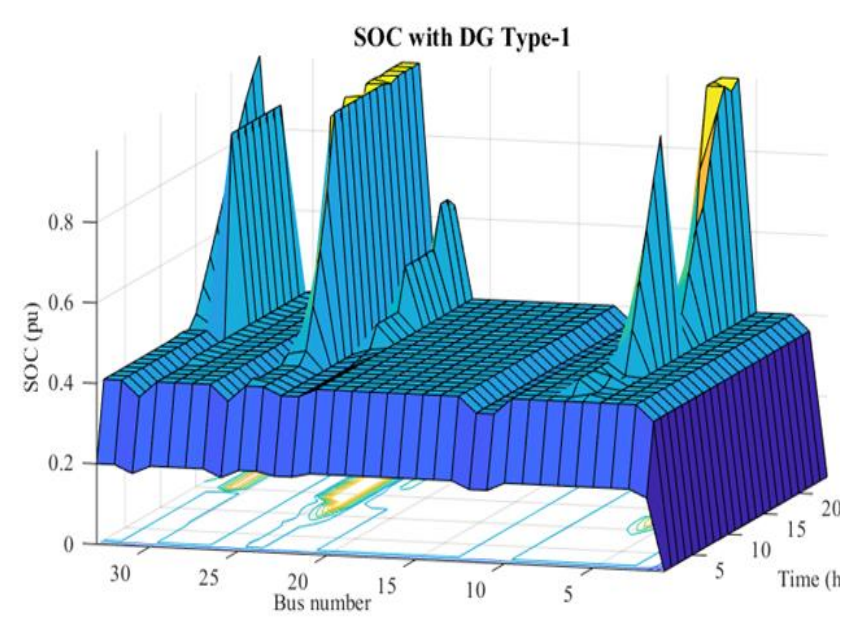

Retrieval Number: E1007069520/2020@BEIESP
Fig. 2. State of charge profile for 24 hours load 33-bus radial distribution system

The lower limit of SOC value is 0.4 in per unit (pu) of (base value of 100) is taken and the maximum value is $1 \mathrm{pu}$ when the battery is fully charged. At the minimum value of SOC battery get charged to maintain the SOC up to 90-100 $\%$, beyond $40 \%$ the battery is fully discharged and it stops supplying the real power. The SOC has been calculated for the battery size of $13.8 \mathrm{kWh}$ battery. The Lithium-ion battery has been taken in to account for the analysis.

\section{2). The size of DG type -3 with battery storage}

The best location of DGs Type -3 with battery storage are selected at bus number 8,20 and 24 . At bus number 8 the highest active power supplied by the diesel generator is in 5th and 23rd hours. Among all the DGs, largest amount of power shared by DG at bus number 20 for 23rd hrs.

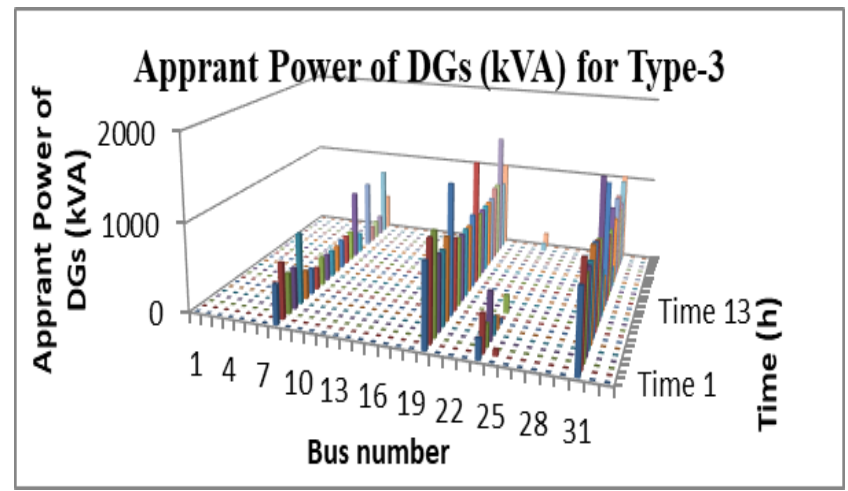

Fig. 10. Apparent power output for DGs Type-3 profile for 24 hours load 33-bus radial distribution system

The size of DGs Type-3 with battery storage obtained are $1200 \mathrm{kVA}$ at $20^{\text {th }}$ bus, $600 \mathrm{kVA}$ at $8^{\text {th }}$ bus and $1000 \mathrm{kVA}$ at $31^{\text {st }}$ bus. The apparent power of DG is shared simultaneously higher at bus number 31 , and at $7^{\text {th }}$ hour the reactive power demand is higher

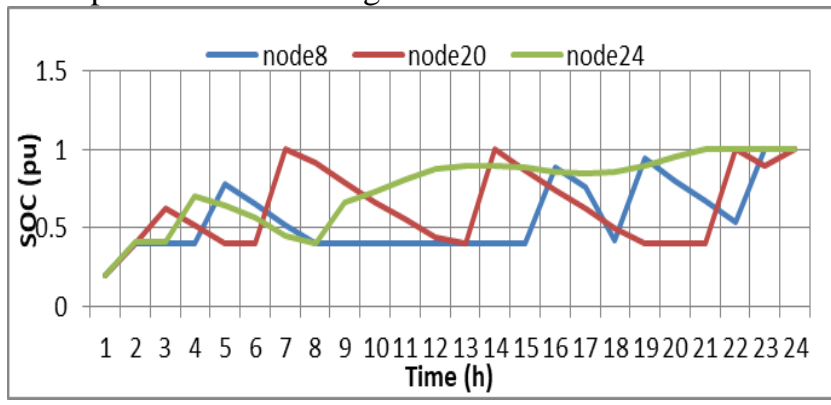

Fig. 11. Result and comparison for SOC at node 8, 20, 24 for DG type 3

Fig.... shows the location of battery storage obtained at bus number 8,20 and $24^{\text {th }}$. The SOC at bus number 8,20 and 24 for $24^{\text {th }}$ hours load duration. In Fig.12 the minimum SOC is maintained at $40 \%$ for safely utilization of battery power. Once diesel generator placed at $8^{\text {th }}$ bus, the load has been shared by the DG, therefor battery remains fullycharged so it represents the highest value of SOC at that time. On the other hand, the SOC at the remaining bus is less, at that time of instant the battery get discharge.

In the Fig.13 the SOC profile shown at bus number

Published By:

Blue Eyes Intelligence Engineering

(C) Copyright: All rights reserved.

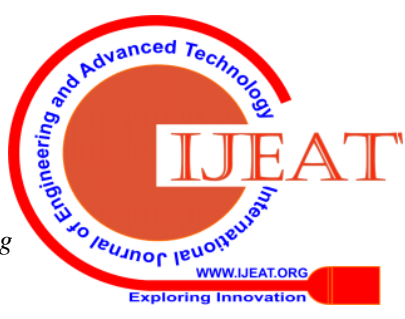


820 and 24, the DGs placed at the bus no 8, 20 and 24. The blue line indicates the SOC at bus no 8 , the battery is charging from $4^{\text {th }}$ to $5^{\text {th }}$ hours and then discharge from $5^{\text {th }}$ to $8^{\text {th }}$ hours as per the load demand. Whereas the red line indicates the battery status at the bus no 20, the battery get initially charge up-to $3^{\text {rd }}$ hour the discharge from $3^{\text {rd }}$ to $5^{\text {th }}$ hour simultaneously.

Table VI Result for DG with battery storage system

\begin{tabular}{|l|l|l|}
\hline & \multicolumn{2}{|l|}{ DG + Battery } \\
\cline { 2 - 3 } & DG type-1 & DG type-3 \\
\hline $\begin{array}{l}\text { Installation } \\
\text { cost of } \\
\text { DG+ Battery } \\
+ \text { Regulator }\end{array}$ & $6978.1 €$ & $6978.1 €$ \\
\hline Total Cost & $14925 €$ & $6.2407 \mathrm{e}+05 €$ \\
\hline
\end{tabular}

\section{Comparison with other method}

The size of DG without battery storage has been shown in Table-VII. The purposed method has been compared with existing method in Table-VII

Table-VII. Result of comparison of existing method and purposed method with DG.

\begin{tabular}{|c|c|c|c|c|}
\hline \multirow[t]{2}{*}{ Method } & \multirow{2}{*}{$\begin{array}{l}\text { Optimal } \\
\text { Locatio } \\
\text { n }\end{array}$} & \multirow{2}{*}{$\begin{array}{l}\text { Optimal } \\
\text { DGs Size } \\
(\mathrm{kW})\end{array}$} & \multicolumn{2}{|c|}{ Losses (kW) } \\
\hline & & & $\begin{array}{l}\text { Without } \\
\text { DG }\end{array}$ & $\begin{array}{l}\text { With } \\
\text { DG }\end{array}$ \\
\hline PSO [2] & 6 & 2590 & 211.20 & 110.10 \\
\hline ELF [25] & 6 & 2600 & 211.20 & 111.10 \\
\hline NM [10] & 6 & 2494.80 & 210.98 & 111.14 \\
\hline $\begin{array}{l}\text { CPLS } \\
{[10]}\end{array}$ & 8 & 1800 & 210.98 & 111.14 \\
\hline & 8 & [2521.8] & 210.98 & 110.63 \\
\hline Proposed & 82425 & $\begin{array}{l}{[1424.9} \\
448.84 \\
420.22]\end{array}$ & 210.98 & 79.356 \\
\hline
\end{tabular}

In this context, the power loss has been reduced to 110.63 $\mathrm{kW}$ with single DG and $79.356 \mathrm{~kW}$ with multiple DG installation respectively. Therefore, power loss has been reduced to $47.59 \%$ with direct approach by using single DG. The power loss has reduced to $62.38 \%$ with direct approach by using multiple DGs.

At bus number 25 the size of DG is $684.3 \mathrm{~kW}$, but the losses are higher in this case, on the other hand at bus number 7, 8, 24 and 25 the losses are reduced.

\section{E. Voltage profile}

The 33-bus radial distribution system using the direct approach for the comparison of direct approach method [14] without DGs and proposed method with DGs for voltage profile shown in Fig 5 . The voltage profile has been improved considerably in the proposed method.

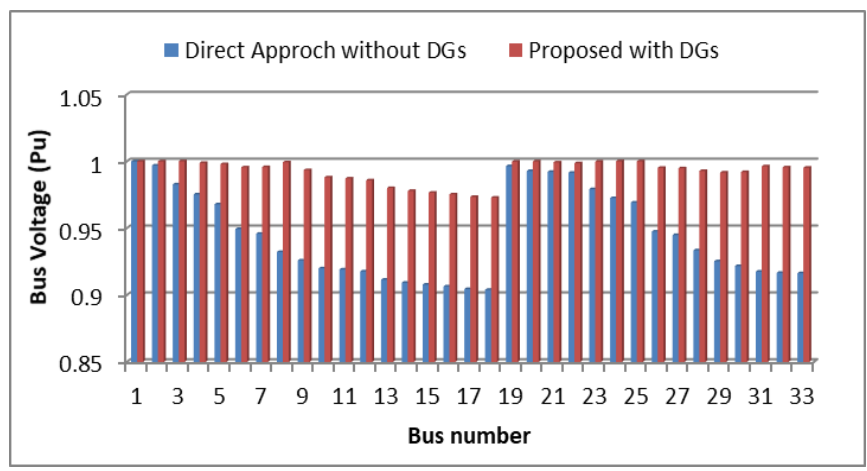

Fig.12 Voltage Profile

The comparison of voltage, the angle at each bus, total power loss and execution time using the direct approach and proposed approach with DGs is given in Table-III. The voltage magnitude in per unit, angle in radian, power loss in $\mathrm{kW}$ unit is given in the Table-III. With the proposed approach, the losses are very low and the execution time has reduced drastically compared to the direct approach in [14].

\section{VI.CONCLUSION}

This paper has presented a novel application of GAMS software to perform the dispatch strategy with optimal location of DG along with battery energy storage device. The two-phase scheme has been proposed for DG and battery allocation in the distribution system. In the first phase, the candidate nodes are selected as the optimal DG location along with battery position and second phase, optimal DG with battery size are computed. The two techniques are used. In first, combined power loss sensitivity (CPLS) has been used for optimal DG location and second, the combined dispatch strategy has been used for placement of the battery. Also, the MINLP solver of GAMS has been used for optimal sizing of DG with battery. The results have been obtaining with and without considering the battery, the PLS limit is changed for finding the optimal location and minimum power loss. The proposed method is tested on IEEE 33-bus test system. In terms of voltage profile and total power loss reduction, the purposed method has superior results than existing methods.

\section{LIST OF SYMBOL}

\begin{tabular}{|c|l|c|l|}
\hline$P_{\text {solar }}$ & $\begin{array}{l}\text { Solar output } \\
\text { power }\end{array}$ & $P_{\text {wind }}$ & $\begin{array}{l}\text { Wind output } \\
\text { power }\end{array}$ \\
\hline$S_{D G}$ & $\begin{array}{l}\text { Set of DG } \\
\text { location }\end{array}$ & $n b$ & $\begin{array}{l}\text { Total number } \\
\text { of buses }\end{array}$ \\
\hline$\delta_{i}$ & $\begin{array}{l}\text { Voltage angle } \\
\text { at bus i }\end{array}$ & $\begin{array}{l}\text { Cut in velocity } \\
\text { of wind, }\end{array}$ \\
\hline
\end{tabular}

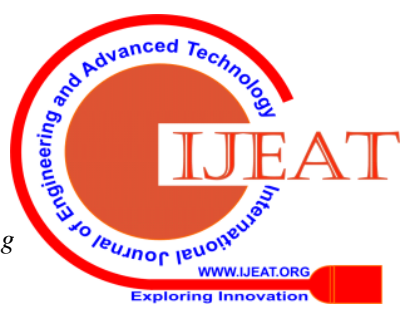




\begin{tabular}{|c|c|c|c|}
\hline$V$ & Rated Voltage & $v_{\text {out }}$ & $\begin{array}{l}\text { cut out velocity } \\
\text { of wind, }\end{array}$ \\
\hline$N_{P V}$ & $\begin{array}{l}\text { Total number } \\
\text { of the solar } \\
\text { panel }\end{array}$ & $S O C_{\min }$ & $\begin{array}{l}\text { minimum state } \\
\text { of charge }\end{array}$ \\
\hline$i$ & Index for bus & $S O C_{\max }$ & $\begin{array}{l}\text { maximum state } \\
\text { of chare }\end{array}$ \\
\hline$k$ & Index for time & $N_{\text {batt }}$ & $\begin{array}{l}\text { total number of } \\
\text { battery }\end{array}$ \\
\hline$P_{d i s_{i}}{ }^{k}$ & $\begin{array}{l}\text { Discharge } \\
\text { power for } i^{\text {th }} \\
\text { bus at } k^{\text {th }} \text { time }\end{array}$ & $D O D_{\text {max _bat }}$ & $\begin{array}{l}\text { maximum } \\
\text { depth } \\
\text { discharge } \\
\text { battery }\end{array}$ \\
\hline$P_{c h i}{ }^{k}$ & $\begin{array}{l}\text { Charge power } \\
\text { for } i^{\text {th }} \text { bus at } k^{\text {th }} \\
\text { time }\end{array}$ & $A, B$ & $\begin{array}{l}\text { Fuel curve } \\
\text { constant }\end{array}$ \\
\hline$\overline{L_{c c}}$ & $\begin{array}{l}\text { Cycle charging } \\
\text { coefficient }\end{array}$ & $P_{\text {NGen }}$ & $\begin{array}{l}\text { Rated power of } \\
\text { Diesel } \\
\text { Generator }\end{array}$ \\
\hline$P d_{\text {net_Load }_{i}}{ }_{i}^{k}$ & $\begin{array}{l}\text { Net DC load for } \\
i^{\text {th }} \text { bus at } \mathbf{k}^{\text {th }} \\
\text { time }\end{array}$ & $p f_{\operatorname{deg}_{i}}$ & $\begin{array}{l}\text { Power factor of } \\
\text { Diesel } \\
\text { Generator }\end{array}$ \\
\hline
\end{tabular}

\section{REFERENCES}

1. D. Q. Hung and N. Mithulananthan, "Multiple distributed generator placement in primary distribution networks for loss reduction," IEEE Trans. Ind. Electron., vol. 60, no. 4, pp. 1700-1708, 2013, doi: 10.1109/TIE.2011.2112316.

2. D. B. Prakash and C. Lakshminarayana, "Multiple DG Placements in Distribution System for Power Loss Reduction Using PSO Algorithm," Procedia Technol., vol. 25, no. Raerest, pp. 785-792, 2016, doi: 10.1016/j.protcy.2016.08.173.

3. A. K. Singh and S. K. Parida, "Combined Optimal Placement of Solar, Wind and Fuel cell Based DGs Using AHP," Proc. World Renew. Energy Congr. - Sweden, 8-13 May, 2011, Linköping, Sweden, vol. 57, pp. 3113-3120, 2011, doi: 10.3384/ecp110573113.

4. G. J. Dalton, D. A. Lockington, and T. E. Baldock, "Case study feasibility analysis of renewable energy supply options for small to medium-sized tourist accommodations," Renew. Energy, vol. 34, no. 4, pp. 1134-1144, 2009, doi: 10.1016/j.renene.2008.06.018.

5. R. Dufo-López and J. L. Bernal-Agustín, "Design and control Energy, vol. 79, no. 1, pp. 33-46, 2005, doi: 10.1016/j.solener.2004.10.004.

6. R. S. Al Abri, E. F. El-Saadany, and Y. M. Atwa, "Optimal placement and sizing method to improve the voltage stability margin in a distribution system using distributed generation," IEEE Trans. Power Syst., vol. 28, no. 1, pp. 326-334, 2013, doi: 10.1109/TPWRS.2012.2200049.

7. S. Kansal, V. Kumar, and B. Tyagi, "Optimal placement of different type of DG sources in distribution networks," Int. J. Electr. Power Energy Syst., vol. 53, no. 1, pp. 752-760, 2013, doi: 10.1016/j.ijepes.2013.05.040.

8. P. Karimyan, G. B. Gharehpetian, M. Abedi, and A. Gavili, "Long term scheduling for optimal allocation and sizing of DG unit considering load variations and DG type," Int. J. Electr. Power Energy Syst., vol. 54, pp. 277-287, 2014, doi: 10.1016/j.ijepes.2013.07.016.

9. Jen-Hao Teng, "A direct approach for distribution system load flow solutions," IEEE Trans. Power Deliv., vol. 18, no. 3, pp. 882-887, 2003, doi: 10.1109/tpwrd.2003.813818.

10. V. V. S. N. Murthy and A. Kumar, "Comparison of optimal DG allocation methods in radial distribution systems based on sensitivity strategies of PV-diesel systems using genetic algorithms," Sol.

approaches,” Int. J. Electr. Power Energy Syst., vol. 53, no. 1, pp. 450-467, 2013, doi: 10.1016/j.ijepes.2013.05.018.

11. K. Vinothkumar and M. P. Selvan, "Distributed generation planning: A new approach based on goal programming," Electr. Power Components Syst., vol. 40, no. 5, pp. 497-512, 2012, doi 10.1080/15325008.2011.647238

12. P. V. Babu and S. P. Singh, "Optimal Placement of DG in Distribution Network for Power Loss Minimization Using NLP \& PLS Technique," Energy Procedia, vol. 90, no. December 2015, pp. 441-454, 2015, doi: 10.1016/j.egypro.2016.11.211.

13. D. Suchitra, R. Jegatheesan, and T. J. Deepika, "Optimal design of hybrid power generation system and its integration in the distribution network," Int. J. Electr. Power Energy Syst., vol. 82, pp. 136-149, 2016, doi: 10.1016/j.ijepes.2016.03.005.

14. S. K. Saraswat, " $10 \mathrm{~kW}$ Solar Photovoltaic - Diesel Hybrid Energy System for Different Solar Zones of India," 2016 Int. Conf. Emerg. Technol. Trends, pp. 1-6, 2016, doi: 10.1109/ICETT.2016.7873692.

15. J. P. Fossati, A. Galarza, A. Martín-Villate, and L. Fontán, "A method for optimal sizing energy storage systems for microgrids," Renew. Energy, vol. 77, pp. 539-549, 2015, doi: 10.1016/j.renene.2014.12.039.

16. S. X. Chen, H. B. Gooi, and M. Q. Wang, "Sizing of energy storage for microgrids," IEEE Trans. Smart Grid, vol. 3, no. 1, pp. 142-151, 2012, doi: 10.1109/TSG.2011.2160745.

17. H. Babazadeh, W. Gao, and K. Duncan, "A new control scheme in a battery energy storage system for wind turbine generators," IEEE Power Energy Soc. Gen. Meet., pp. 1-7, 2012, doi: 10.1109/PESGM.2012.6345722.

18. Z. Di, M. Yan, B. Qing-Wen, D. Zhang, Y. Ma, and Q.-W. Bai, "Estimation of Lithium-ion battery state of charge," Proc. 30th Chinese Control Conf., pp. 6256-6260, 2011.

19. Y. M. Atwa, E. F. El-Saadany, M. M. A. Salama, R. Seethapathy, M. Assam, and S. Conti, "Adequacy evaluation of distribution system including wind/solar DG during different modes of operation," IEEE Trans. Power Syst., vol. 26, no. 4, pp. 1945-1952, 2011, doi: 10.1109/TPWRS.2011.2112783.

20. Y. Zhang, Y. Xu, H. Yang, and Z. Y. Dong, "Voltage regulationoriented co-planning of distributed generation and battery storage in active distribution networks," Int. J. Electr. Power Energy Syst., vol. 105, no. May 2018, pp. 79-88, 2019, doi: 10.1016/j.ijepes.2018.07.036.

21. L. A. Bird, K. S. Cory, and B. G. Swezey, "Renewable Energy PriceStability Benefits in Utility Green Power Programs," Nrel, no. August, 2008.

22. [22] IRENA International Renewable Energy Agency, Renewable Power Generation Costs in 2017. 2018

23. N. R. E. Laboratory, "Distributed Generation Renewable Energy Estimate of Costs Database," 2013, [Online]. Available http://www.nrel.gov/analysis/tech_lcoe_re_cost_est.html.

24. M. H. Mostafa, S. H. E. A. Aleem, S. G. Ali, A. Y. Abdelaziz, P. F. Ribeiro, and Z. M. Ali, "Robust energy management and economic analysis of microgrids considering different battery characteristics," IEEE Access, vol. 8, pp. 54751-54775, 2020, doi 10.1109/ACCESS.2020.2981697.

25. K. D. Mistry et al., "Optimal placement of DG in radial distribution systems based on new voltage stability index under load growth," Int J. Electr. Power Energy Syst., vol. 69, no. 1, pp. 246-256, 2012, doi: 10.1016/j.ijepes.2014.12.080.

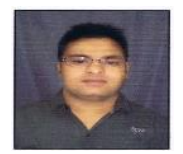

\section{AUTHORS PROFILE}

Bharat Singh: Received his B.Tech degree form GBPEC Pauri, UK in 2012 and M.Tech degree from NIT Hamirpur, India in 2016. He is currently pursuing Ph.D. from Electrical Engineering department in NIT Kurukshetra from 2018. His area of interest includes the dispatch strategy of Micro-Grid. He is life time member of Indian Society for Technical Education (ISTE) and Member of IEEE.

Satyaveer Singh Rawat: Received his Bachelor of Engineering degree in

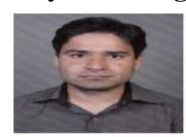
Electrical Engineering form GBPEC Pauri, Uttarakhand, India in 2008 and M.Tech degree from IIT Khargpur, India in Power \& Energy specialization of Department of Electrical Engineering in 2015. He is currently working as an Assistant Professor in Department of Electrical Engineering at G.B. Pant Institute of Engineering \& Technology (formerly GBPEC) from 2009. His

Published By:

Blue Eyes Intelligence Engineering

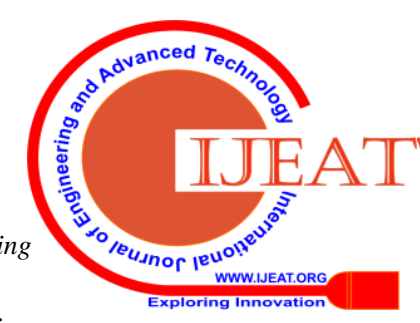


area of interest includes Distributed Generation and Integration with grid ,Wind Energy Integration with Grid, Solar PV Technology, Smart Grid and Micro Grid Operations, Operation of Grid Connected Microgrid, Operation of Islanded Microgrid. He is life time member of Indian Society for Technical Education (ISTE)

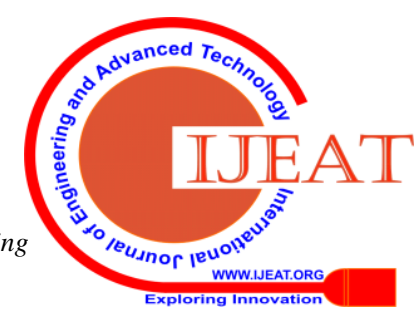

